Books, videos, CD-ROMs, DVDs and any other relevant items submitted for a review in the $B D J$ should be addressed to: Kate Maynard, Assistant Editor, British Dental Journal, NPG, 4-6 Crinan Street, London N1 9XW

\section{Paediatric cariology}

C. Deery, M-T. Hosey, P. Waterhouse
UK: Quintessence
price $£ 28$, pp 140
ISBN 1850970734

With all good intentions, I planned to read Paediatric cariology while on holiday in Italy. Remarkably I did manage it, which is testimony enough to the readability of this excellent little textbook.

The authors set out to provide a comprehensive guide to the diagnosis and management of caries in children. They have certainly achieved this aim and have produced a very well illustrated, concise and practical book. General dental practitioners and professionals complementary to dentistry would undoubtedly find it a very useful addition to their reference collection. It was particularly encouraging that, right from the opening pages, the authors provide a strong argument for the need to be proactive in the management of the carious primary dentition.

The first four chapters essentially cover the diagnosis and prevention of dental caries. I found the sections on caries risk assessment (chapter 2) and the caries prevention toolkit (chapter 4) especially informative. I think readers would also appreciate the practical and sensible advice that is given on how to manage the child who presents with toothache (chapter 3).

The remaining five chapters provide extremely helpful instruction relating to restorative management of the carious primary dentition. One of the strengths of this book is that it offers such a good range of evidence-based and readily attainable treatment options. A nice example of such is atraumatic restorative treatment (chapter 5) which may be indicated for young, anxious or less compliant children.

The chapter on pulp therapy (chapter 7) proved very topical. There has been growing unease about the use of formocresol for vital primary molar pulp treatment and this controversial issue was thoroughly addressed. The authors discuss the rationale for a number of different pulp treatments and provide strong argument for use of ferric sulphate as a more biologically acceptable alternative to formocresol. Clear details and valuable clinical tips are given for each pulp therapy regimen.

Other infrequently employed techniques for children, such as preformed crowns and rubber dam, are also presented in such a simple and clear way that practitioners may well be persuaded to try them out in the future!

In summary, this is a brightly illustrated and well-written textbook, which provides contemporary and highly practical guidance on all aspects of caries management. It is a 'must' for anyone wanting to achieve stress-free and successful clinical management of their young patients.

H. Rodd

\section{Fixed prosthodontics in dental practice}

\section{O'Sullivan \\ UK: Quintessence \\ price £28, pp 162}

ISBN 1850970955

This compact, well-illustrated text weighs in at fewer than 200 pages. It is a multi-author work but, unlike many books of this nature, remains cohesive with a uniform style throughout. This book covers a specific area but is designed to sit within a series of similar texts dealing with other aspects of dental practice, and as such it has a generic cover style.

The book begins with a useful preface setting out the aims and objectives, which in my opinion the authors go on to meet. The order of the chapters follows the usual clinical sequence in the provision of fixed prostheses and rightly begins with the important topic of patient assessment and treatment options. The reader is then taken in turn through the remaining stages culminating in factors influencing the choice and use of luting cements. The book concludes with two summary chapters on resin-bonded restorations, and the restoration of non-vital teeth. These are by necessity brief, and as such are only able to deal with the basic aspects of the subject matter. However, they will be useful to those who wish to be brought up to date with current accepted practice.

Rightly, this book does not attempt to cover fixed prosthodontics in relation to implantology, and this is dealt with by other volumes in the series.

It would of course be extremely rare to read a text with which the reviewer was in complete agreement. As always there are aspects of the authors' approaches to particular clinical situations which are likely to stimulate debate and disagreement, and others that require more robust evidence to back up particular statements. This surely will always be the case with clinical dentistry in general and fixed prosthodontics in particular.

In summary this book is a welcome addition to the field, easy to read and containing much sensible and practical advice. I am sure that it will prove popular with senior students and experienced dental practitioners who have an interest in fixed prosthodontics, and who wish to acquaint themselves with contemporary practice in this field.

P. Smith 

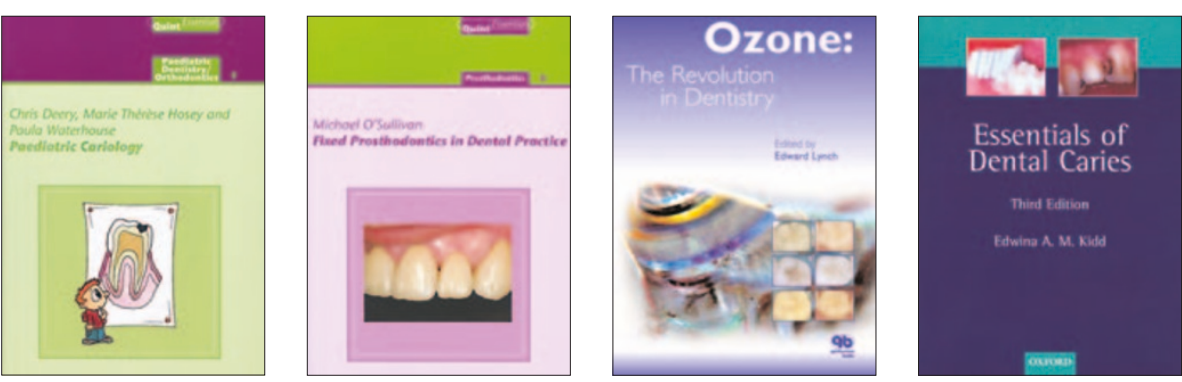

\section{Ozone: The revolution in dentistry}

\author{
E. Lynch (Ed) \\ UK: Quintessence \\ price $€ 65$, pp 288 \\ ISBN 1850970882
}

Ozone is well established in many fields such as medicine, water quality treatment and fresh food storage, so it is surprising that its appearance on the dental stage has been so long coming. However, clearly it is now here to stay. It enables clinicians to begin to turn away from the 'Dark Ages' of tissue amputation and presents us with a gold standard of prevention and disease reversal. A technique which is extremely safe, predictable and easy will mean that every clinician will want to incorporate it into their armamentarium.

More than 5,000 clinicians now using ozone in their practices have waited for an authoritative text for some time and will not be disappointed. It is of course entirely appropriate that it falls to Professor Edward Lynch to bring his depth of experience and obvious enthusiasm to collate and edit the work of the many contributors. As you would expect, Quintessence has produced a volume which is clearly presented and, by breaking the subject down into manageable chapters, an enjoyable read. Much of the clinical photography is of an especially high standard. I found myself totally absorbed and inspired by the beautifully presented work of Liviu and Gabriela Steier on their use of ozone as an adjuvant for long term success in restorative dentistry, along with the exciting potential of ozone in root canal treatment.

The text features contributors from many different scientific and geographical backgrounds. It is encouraging to see how the clinicians featured have incorporated ozone into their practices.

No work on ozone could ever be complete without sections on Minimal intervention dentistry, Modified ART technique, Airabrasion,

Remineralisation and of course the earliest possible diagnosis of caries using Diagnodent. All of these subjects are covered in detail; again well illustrated.

While I am reassured to see the complexities of ozone chemistry and nuclear magnetic resonance explained so comprehensively, I cannot personally claim a full understanding of them. These early chapters certainly complete their objective in giving the more technically minded reader a thorough overview of this compelling subject. The foreword poses a question: 'Is the new ozone treatment a quantum leap?' The answer is that since a 'quantum leap' is in fact the smallest possible measurement of change, I would not agree. I actually think ozone and its complementary treatment modalities will permanently change the face of dentistry for the better, for patients and clinicians alike. This is a 'must have' text for twenty-first century dentists.

\section{K. Hayes}

\section{Essentials of dental caries}

\section{E. A. M. Kidd \\ UK: Oxford University Press \\ price $€ 29.95$, pp 180 \\ ISBN 0198529783}

Many individuals involved in dental education worry about the teaching of cariology to students. Although caries results in so much treatment, the process is generally poorly understood.

Undergraduates feel more comfortable talking about the physical properties of a composite resin than the process that led to it being required. However, a few dental leaders have pioneered integrated caries research with teaching and Edwina Kidd is one such leader. Now in its third edition, the text is aimed at the undergraduate and those preparing for initial postgraduate studies, such as MFDS. Slightly slimmer than the second edition at 180 pages, it has been extensively rearranged. The diagnosis section is a particular strength of the text, as are the sections on fluoride and saliva. The text is only minimally referenced, although there are sufficient pointers for interested readers to take their studies forward. The book benefits from numerous clinical photographs and clear line drawings which serve to illustrate the narrative well. The histology section is an excellent example of this and a good place to start for those aiming to revise their knowledge of dental hard tissues.

The clinical management of caries is restricted to a single chapter at the end of the text and describes the use of rubber dam, fissure sealants and the placement of temporary dressings in an attempt to arrest and stabilise the progression of the disease. This section is very much an overview and readers would need to consult additional texts in order to understand the management process completely. Indeed, the management of deep carious lesions and the removal or otherwise of carious dentine is a contentious issue, and students should always check with their teachers before pursuing a treatment methodology. This may however change, as a recent systematic review found that partial caries removal in symptomless teeth did not result in increased pulpal symptoms.

This is a highly accessible entry-level text which achieves its stated goals of providing the "essentials of dental caries'. It is recommended to all undergraduates and those pursuing the first stages of postgraduate work.

I. A. Pretty 